\title{
Associations of Polymorphic Variants of the Biotransformation Genes with the Components of the Glutathione System in Men with Infertility
}

\author{
N.A. Kurashova, $\mathrm{PhD}^{* 1}$; M.I. Dolgikh, $\mathrm{PhD}^{1}$; O.A. Ershova, $\mathrm{PhD}^{1}$; O.A. Gavrilova ${ }^{1}$; \\ E.V. Osipova, $\mathrm{PhD}, \mathrm{ScD}^{1}$; B.G. Dashiev²; T.A. Bairova, $\mathrm{PhD}, \mathrm{ScD}^{1}$; \\ S.I. Kolesnikov, $\mathrm{PhD}, \mathrm{ScD}^{1,3}$; L.I. Kolesnikova, $\mathrm{PhD}, \mathrm{ScD}^{1}$ \\ ${ }^{I}$ Scientific Centre for Family Health and Human Reproduction Problems, Irkutsk, the Russian Federation \\ ${ }^{2}$ Republican Perinatal Center, Ulan-Ude, the Russian Federation \\ ${ }^{3}$ Lomonosov Moscow State University, Moscow, the Russian Federation
}

\begin{abstract}
The aim of this research was to investigate the glutathione system components and their association with polymorphisms GST genes in men with infertility.

Materials and Methods: One hundred and sixty Russian men of reproductive age (Caucasians) who came to the public health institution Republican Perinatal Center in Ulan-Ude with an infertility problem of one year and more after marriage were included in the main group. The control group included 104 men with proven fertility. DNA samples were genotyped for polymorphisms in GSTP1, GSTT1 and GSTM1genes and activity of glutathione system enzymes was determined.

Results: The most informative genetic and metabolic indicators in Caucasian males with infertility were combinations of the null genotypes $\operatorname{GSTT1}\left({ }^{*} 0 /{ }^{*} 0\right)+G S T M 1\left(* 0 /{ }^{*} 0\right)$ associated with a decrease of GST activity in blood and ejaculate and an increase of GSH and GPO in the blood. Another combination is GSTP1(Ile105Val)+GSTP1(Ala114Val), which is associated with suppression of the blood and ejaculate GPO activity and a decrease in blood concentration of GSH. (International Journal of Biomedicine. 2017;7(3):226-230.)
\end{abstract}

Key words: male infertility • GSTP1 • GSTM1 • GSTT1 • glutathione

\section{Abbreviations}

AFO, active forms of oxygen; DNA, deoxyribonucleic acid; GST, glutathione S-transferase; GPO, glutathione peroxidase; GR, glutathione reductase; $\mathbf{O S}$, oxidative stress.

\section{Introduction}

Genetic factors cause $30 \%-50 \%$ of cases of male infertility in different forms. ${ }^{(1-3)}$ The development of molecular biology, biotechnology and gene engineering evoked significant progress in the research mechanisms to control gene expression, which are involved in physiological and pathological processes. Studies aimed at a search for

*Corresponding author: Nadezhda A. Kurashova, PhD. Scientific Centre for Family Health and Human Reproduction Problems, Irkutsk, the Russian Federation. E-mail: nakurashova@, yandex.ru associations between peculiarities of gene polymorphisms and different forms of reproductive function disorder are becoming more relevant. ${ }^{(4-6)}$ Much attention is given to study of the polymorphic variants of the "susceptibility" genes, which, in contrast to mutations, are not evident in the phenotype, but they are not always neutral and often lead to an appearance of metabolic products with modified physical and chemical features and parameters of functional activity.(7) Genetic polymorphisms of biotransformation enzymes determine the intensity of the accumulation of genotoxic metabolites in the cells, participating in DNA damage and control of the enzymes, which detoxify free radicals and enable homeostasis in cells and tissues. Susceptibility of the organism to adverse 
effects of the environment is highly dependent on the activity of the xenobiotic detoxification enzymes. ${ }^{(8,9)}$ Depending on genetically determined peculiarities of xenobiotic biotransformation, its interaction with receptors and enzyme systems, detoxification enzymes define the body's reaction to various toxic substances and pharmaceuticals. ${ }^{(10-14)}$

The glutathione S-transferase (GST) genes (GSTM1, GSTT1, and GSTP1) are involved in the detoxification of a broad range of toxic substances. Polymorphisms in GST genes can affect the expression levels of the GST enzymes. Since GST enzymes play a vital role in cellular defense against environmentally toxic compounds, polymorphisms of GST genes can increase subsceptibility to diseases caused by such xenobiotics. GSTM1 and GSTT1 genes show deletion polymorphism. ${ }^{(15)}$ Thesehomozygous genedeletions, called null genotypes, are denoted as GSTM ${ }^{*} 0 / * 0$ and $G S T T 1 * 0 / * 0$. The percentage of individuals who do not express the GSTM1 enzyme due to a homozygous gene deletion is higher in Caucasians and Asians than in Africans. ${ }^{(16-18)}$ About $60 \%$ of Asians, $40 \%$ of Africans and $20 \%$ of Caucasians do not express the GSTT1 enzyme. ${ }^{(19)}$ The GSTP1 gene has polymorphism loci within its coding region: GSTP1 Ile105Val polymorphism in exon 5 and GSTP1 Ala114Val polymorphism in exon 6. ${ }^{(20,21)}$ Polymorphisms within GSTP1 are also associated with alterations in enzyme activity.

The aim of this research was to investigate the glutathione system components and their association with polymorphisms GST genes in men with infertility.

\section{Materials and Methods}

One hundred and sixty Russian men of reproductive age (Caucasians) who came to the public health institution Republican Perinatal Center in Ulan-Ude with an infertility problem of one year and more after marriage were included in the main group. The control group included 104 men with proven fertility. All men had a laboratory and clinical examination by an andrologist, including an ultrasonic scan of scrotum and prostate. Macroscopic and microscopic examination of ejaculate was performed in accordance with with the WHO recommendations (2010). The study was conducted in accordance with ethical principles of the Declaration of Helsinki (2000) and approved by the Republican Perinatal Center (Ulan-Ude) Ethics Committee. Written informed consent was obtained from all participants.

Patients with the genetic causes of infertility were excluded from the research (AZF-deletions, CFTR-mutations, mutational changes of the number of $\mathrm{CAG}$ repeats, controlled by androgen receptors).

Concentration of the reduced (GSH) and oxidized (GSSG) glutathione was determined by the method of $\mathrm{P}$. Hissin. (22) The activity of GST, GPO and GR was determined using Randox reagents. ${ }^{(23-25)}$ The concentration of conjugates during the reaction was registered spectrophotometrically with a wavelength of $340 \mathrm{~nm}$ using a Shimadzu RF-1501 spectrofluorophotometer.

DNA samples were genotyped for polymorphisms in GSTP1, GSTT1 and GSTM1 genes. DNA was isolated from venous blood samples using the sorbent method with the certified reagent kit DNA-Sorb-B (Central Research Institute of Epidemiology, Moscow, Russia). Genetic polymorphism of insertion/deletion (I/D) in the GSTT1 and GSTM1 genes was determined by PCR in the automatic thermocycler Tercyc using the reagent kit of Central Research Institute of Epidemiology(Moscow, Russia).

Deletion status of GSTM1 and GSTT1 was simultaneously determined by a multiplex polymerase chain reaction method. ${ }^{(26)}$ To determine the genotypes at codon 105 and 114, respectively, the exon 5 and exon 6 of the GSTP1 gene were amplified using the relevant primers. Amplification products were detected in $3 \%$ agarose gel; the electrophoresis results were registered and documented with the help of the system of computer gel documentation GelDoc. GSTM1+, GSTT1+ (wild type) and GSTM1*0 and GSTT1*0 homozygotes (null genotype) were analyzed.

The statistical analysis was performed using the statistical software STATISTICA 6.1 (StatSoft Inc., USA). Intergenic interaction of the polymorphic variants of the examined genes was estimated with the help of the bioinformatic method of multifactor modelling of genomic interactions - multifactor dimensionality reduction (MDR) in the open access program MDR 3.0.2. The MDR-method allows assessment simultaneously affecting the disease interaction of all examined alleles of the gene polymorphic variant, and decreases the dimension of the number of calculated parameters on the basis of creation of new variables, with assessment of how a combination of genotypes impacts the risk of developing disease.

\section{Results and Discussion}

We conducted a comprehensive search using the MDRmethod with assessment of all possible combinations of the DNA markers and defined crucial models of intergenic interactions (polymorphic locus combination) for men with infertility defined (Fig. 1).

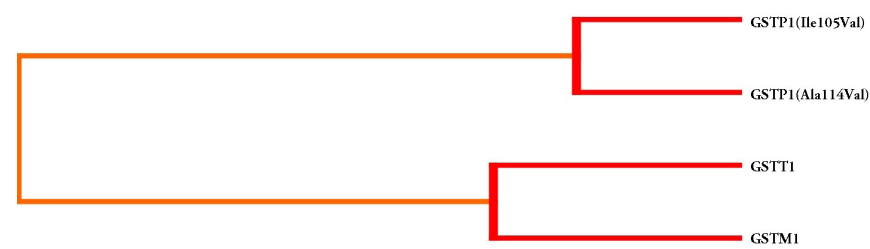

Fig. 1. Dendrogram of intergenic interactions of polymorphic locus combination in men with infertility.

As we can see from the dendrogram and Table 1, the individual marker of development of reproductive disorders for Russian men is carriage of the combination of the polymorphisms GSTT1 $(* 0 / * 0)+G S T M 1(* 0 / * 0)$ and GSTP1(Ile 105Val) + GSTP1(Ala114Val)

Established synergic interactions of the polymorphic variants of xenobiotic detoxification genes lead to complete absence of the relevant protein or to appearance of enzymes with modified, usually lower, levels of activity. Taking 
into account these data, we performed an analysis of the functionality of the glutathione system in men with infertility.

Table 1 .

Entropy value of polymorphic variants of xenobiotics detoxification system genes in various combinations in men with infertility

\begin{tabular}{|l|c|}
\hline \multicolumn{1}{|c|}{ Polymorphic variants of genes } & $\begin{array}{c}\text { Caucasians } \\
(\mathrm{n}=164)\end{array}$ \\
\hline GSTT1 $(* 0 / * 0)+\mathrm{GSTM} 1 * 0 / * 0)$ & $0.70 \%$ \\
\hline GSTP1(Ala114Val)+GSTM1 $(* 0 / * 0)$ & $0.69 \%$ \\
\hline GSTP1(Ile105Val)+GSTP1(Ala114Val) & $1.06 \%$ \\
\hline GSTP1(Ile105Val)+GSTT1 $(* 0 / * 0)$ & $0.22 \%$ \\
\hline
\end{tabular}

Activities of the antioxidant enzymes are balanced and closely connected to each other. ${ }^{(19)}$ Disproportion in the enzyme components of the antioxidant defense may lead to additional generation of AFO and be one of the causes of OS. ${ }^{(20)}$ Not only do GST enzymes catalyze glutathione accession to the electrophilic center of various chemical compounds, making them less toxic, but also have some peroxidase activity, which plays an important role in intracellular fixation and transportation of a large amount of both endogenous and exogenous compounds.

According to our results, in the main group, those who carried a combination of the null genotypes $\operatorname{GSTT1}(* 0 / * 0)+\operatorname{GSTM1}(* 0 / * 0)$ demonstrated a statistically significant decrease in serum levels of GSH $(\mathrm{P}=0.003)$ and GST $(\mathrm{P}=0.004)$, an increase in serum level of GPO $(\mathrm{P}=0.04)$, and a decrease in GST level ( $\mathrm{P}=0.01)$ in the ejaculate (Fig. 2).

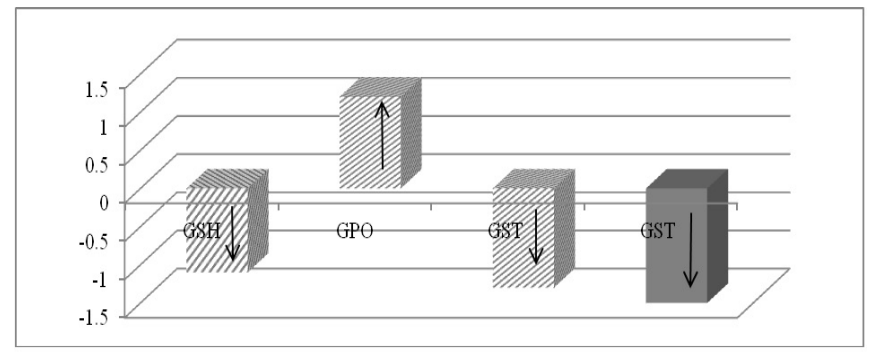

Fig. 2. Changes in levels of GST enzymes in the main group, those who carried a combination of the null genotypes $\operatorname{GSTT1}(* 0 / * 0)+\operatorname{GSTM1}(* 0 / * 0)(P<0.05)$.

Reduction in hydroperoxides content by GPO and GST activity prevents the progression of peroxidation and the appearance of its secondary metabolites. GSTs are an abundant family of dimeric proteins, which have the capacity to conjugate glutathione (GSH) with a variety of electrophilic compounds, primarily produced from exogenous xenobiotics by biotransformation but which can also arise from endogenous substances.

In the main group, those who carried a combination of polymorphisms GSTP1(Ile105Val)+GSTP1(Ala114Val) demonstrated a statistically significant decrease in serum levels of GSH and GPO $(\mathrm{P}=0.04)$ and a decrease in GPO level $(\mathrm{P}=0.02)$ in the ejaculate (Fig. 3).

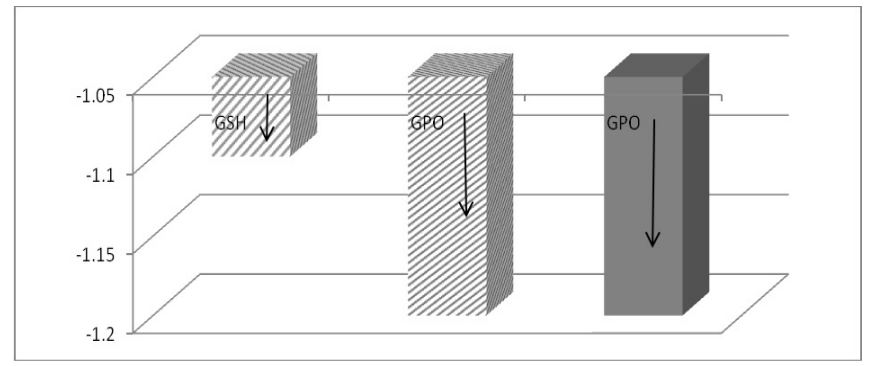

Fig. 3. Changes in levels of GST enzymes in the main group, those who carried a combination of GSTP1(Ile105Val) +GSTP1 (Ala114Val) $(P<0.05)$.

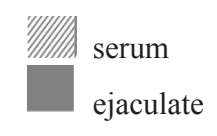

The discovered changes of the components of the glutathione system in males with infertility characterize the functional load augmentation in antioxidant systems. GSTs cannot neutralize the toxic impact of various hydrophobic and electrophilic compounds because of their broad substrate specificity and involvement in the metabolism of many endogenous and exogenous electrophilic compounds by conjugation with glutathione.

Two main blood enzymes of the glutathione system associated both with carriage of the combination of the null genotypes GSTT1 $(* 0 / * 0)+\operatorname{GSTM} 1(* 0 / * 0)$ and GSTP1(Ile10 $5 \mathrm{Val})+$ GSTP1(Ala114Val polymorphisms were reduced, but in the ejaculate only one enzyme encoding the mentioned polymorphisms was reduced, which can be considered as a compensatory ejaculate reaction to the impact of damaging factors.

\section{Conclusion}

In human testis, reactive oxygen species are involved in the pathogenesis of male reproductive processes by inducing OS that can damage male germ cellular lipids, protein, and DNA. ${ }^{(8,10,11,27,28)}$ Antioxidants, such as GSTM1 and GSTT1, can reduce the toxic effects of OS on male germ lines, suggesting that these two antioxidants genes may play a protective role against OS in spermatogenesis. ${ }^{(12)}$ Thus, the deletion polymorphisms of GSTM1 and GSTT1 are considered as candidates for genetic susceptibility factors for male infertility. The results showed that the null genotype of GSTM1 is associated with male infertility, especially in Caucasians and Chinese, indicating that the null genotype of GSTM1 could increase the risk of male infertility. ${ }^{(11,12)}$

The interaction between genetic factors (some gene mutations) and the environmental factors (xenobiotics) may play a role in the impaired spermatogenesis and affect the male reproductive function. ${ }^{(29,30)}$ The intake of xenobiotics is different due to diet and pollution conditions, which may result in the different effect of the null genotype of GSTT1 on male infertility among populations. ${ }^{(12)}$

Genetically determined imbalance in the system of the glutathione-dependent antioxidant defense determines lipid peroxidation activation and facilitates a significant weakening of metabolic and detoxifying functions of the 
organism. As a result, the susceptibility of cells to operations with xenobiotics' harmful influence is significantly increasing, adversely affecting spermatogenesis.

In our study, the most informative genetic and metabolic indicators in Caucasian males with infertility were combinations of the null genotypes $G S T T 1(* 0 / * 0)+G S T M 1(* 0 / * 0)$ associated with a decrease of GST activity in blood and ejaculate and an increase of GSH and GPO in the blood. Another combination is GSTP1(Ile105Val)+GSTP1(Ala114Val), which is associated with suppression of the blood and ejaculate GPO activity and a decrease in blood concentration of GSH.

Genetically determined peculiarities in how the xenobiotic biotransformation system functions make each individual unique with regard to their adaptive capacity resistance or sensitivity to the damaging exo- and endogenous factors. Identification of carriage of the polymorphic variants of the GSTT1 and GSTM1, as well as determination of the enzymes of the thiol-disulfide system, can be recommended for additional estimation of the risk of developing a disorder of the reproductive functions in males.

\section{Competing interests}

The authors declare that they have no competing interests.

\section{References}

1. Huseynova KA, Shishimorova MS. [Violations of reproductive function for men, related to anomalies of sexual chromosomes]. Reproduktivnaia Meditsina. 2014;3-4(20):5659. [Article in Russian].

2. Iskhakova GM, Izmaylova SM, Izmaylov AA. [Genetic aspects of male infertility. Sovremennye problemy nauki i obrazovaniya]. 2015;3:85. [Article in Russian].

3. Nuti F, Krausz C. Gene polymorphisms/mutations relevant to abnormal spermatogenesis. Reprod Biomed Online. 2008;16(4):504-13.

4. Faizullin LZ, Tazhetdinov OKh, Karnaukhov VN, Ovchinnikov RI, Popova AYu, Nikitin PD, et al. [Role of aromatase gene (CYP 19) polymorphism in the development of infertility in obese males]. Obstetrics and Gynecology. 2013;10:76-80. [Article in Russian].

5. Dyuzhev JA, Lipin MA, Polyakov AV, Posiseeva LV, Fetisova I.N. [The Polymorphisms of Gluthatione-STransferase Genes GSTM1, GSTT1 and GSTP1 in Men with Primary Infertility]. Vestnik Novikh Meditsinskikh Tekhnologii. 2007;1:112. [Article in Russian].

6. Wainer AS, Nagaitsev VM, Korolkova OV, Vostrikov VV, Osadchuk LV, Pechkovsky YeV, et al. [Polymorphism rs3088232 in the BRDT gene is associated with idiopathic male infertility in the West Siberian Region of Russia]. Bulletin of Siberian Medicine. 2012;11(3):18-21. [Article in Russian].

7. Baranov VS, Baranova EV, Ivashchenko TE, Evseev MV. Human genome and genes "predisposition". Introduction to predictive medicine. SPb.: Intermedika; 2000. [in Russian].

8. Josephy PD. Genetic variations in human glutathione transferase enzymes: significance for pharmacology and toxicology. Hum Genomics Proteomics. 2010;2010:876940. doi: 10.4061/2010/876940.

9. Polonikov AV, Ivanov VP, Solodilova MA. Genetic variation of genes for xenobiotic-metabolizing enzymes and risk of bronchial asthma: The importance of gene-gene and gene-environment interactions for disease susceptibility. J Hum Genet. 2009;54(8):440-9. doi: 10.1038/jhg.2009.58.

10. Kolesnikova LI, Kurashova NA, Bairova TA, Dolgikh MI, Ershova OA, Natyaganova LV, et al. Features of Lipoperoxidation, Antioxidant Defense, and Thiol/Disulfide System in the Pathogenesis of Infertility in Males, Carriers of Nonfunctional Variants of GSTT1 and GSTM1 Gene Polymorphisms. Bull Exp Biol Med. 2017;163(3):378-380. doi: $10.1007 /$ s 10517-017-3808-9.

11. Safarinejad MR, Dadkhah F, Ali Asgari M, Hosseini SY, Kolahi AA, Iran-Pour E. Glutathione S-transferase polymorphisms (GSTM1, GSTT1, GSTP1) and male factor infertility risk: a pooled analysis of studies. Urol J. 2012;9(3): 541-8.

12. Ying HQ, QiY, PuXY, Liu SR,AZC.Association of GSTM1 and GSTT1 genes with the susceptibility to male infertility: result from a meta-analysis. Genet Test Mol Biomarkers. 2013;17(7):535-42. doi: 10.1089/gtmb.2012.0409.

13. Wu QF, Xing JP, Sun JH, Xue W, Wang XY, Jin XJ. [Genetic polymorphism of glutathione S-transferase T1 associated with idiopathic azoospermia and oligospermia]. Zhonghua Nan $\mathrm{Ke}$ Xue. 2007 May;13(5):407-10. [Article in Chinese]

14. Tirumala Vani G, Mukesh N, Siva Prasad B, Rama Devi P, Hema Prasad M, Usha Rani P, et al. Role of glutathione S-transferase Mu-1 (GSTM1) polymorphism in oligospermic infertile males. Andrologia. 2010;42(4):213-7. doi: 10.1111/j.1439-0272.2009.00971.x.

15. Nelson HH, Wiencke JK, Christiani DC, Cheng TJ, Zuo ZF, Schwartz BS, et al. Ethnic differences in the prevalence of the homozygous deleted genotype of glutathione S-transferase theta. Carcinogenesis. 1995;16:1243-5.

16. Bailey LR, Roodi N, Verrier CS, Yee CJ, Dupont WD, Parl FF. Breast cancer and CYP1A1, GSTM1, and GSTT1 polymorphism: evidence of a lack of association in Caucasians and African Americans. Cancer Res. 1998;58(1):65-70.

17. Roth MJ, Dawsey SM, Wang G, Tangrea JA, Zhou B, Ratnasinghe D, et al. Association between GSTM $1 * 0$ and squamous dysplasia of the esophagus in the high risk region of Linxian, China. Cancer Lett. 2000;156(1):73-81.

18. Cho HJ, Lee SY, Ki CS, Kim JW. GSTM1, GSTT1 and GSTP1 polymorphisms in the Korean population. J Korean Med Sci. 2005;20(6):1089-92.

19. Strange RC, Fryer AA. The glutathione S-transferase: influence of polymorphism on cancer susceptibility. In: Vineis P, editor. Metabolic polymorphism and susceptibility to cancer. Lyon France: IARC Scientific Publication; 1999:231-249.

20. Ali-Osman F, Akande O, Antoun G, Mao JX, Buolamwini J. Molecular cloning, characterization, and expression in Escherichia coli of full length cDNAs of three human glutathione S-transferase $\mathrm{Pi}$ gene variants. Evidence for differential catalytic activity of the encoded proteins. J Biol Chem. 1997;272(15):10004-12.

21. Harries LW, Stubbins MJ, Forman D, Howard GC, Wolf CR. Identification of genetic polymorphisms at the glutathione S-transferase $\mathrm{Pi}$ locus and association with susceptibility to bladder, testicular and prostate cancer. Carcinogenesis. 1997;18(4):641-4.

22. Hissin HY, Hilf R. A fluometric method for determination of oxidized and reduced glutathione in tissues. Anal Biochem. 1976; 74(1):214-26.

23. Sundberg AG, Appelkvist EL, Bäckman L, Dallner G. 
Quantitation of glutathione transferase-pi in the urine by radioimmunoassay. Nephron. 1994;66(2):162-9.

24. Paglia DE, Valentine WN. Studies on the quantitative and qualitative characterization of erythrocyte glutathione peroxidase. J Lab Clin Med. 1967;70(1):158-69.

25. Goldberg DM, Spooner RJ. Glutathione Reductase. In: Bergmeyer HU, Bergmeyer J, Grab M (Eds.) Methods of enzymatic analysis, 3rd Edition, Verlag Chemie, Weinheim; 1983:258-265.

26. Abdel-Rahman SZ, el-Zein RA, Anwar WA, Au WW. A multiplex PCR procedure for polymorphic analysis of GSTM1 and GSTT1 genes in population studies. Cancer Lett. 1996;107(2):229-33.

27. Aitken RJ, Gordon E, Harkiss D, Twigg JP, Milne P,
Jennings Z, Irvine DS. Relative impact of oxidative stress on the functional competence and genomic integrity of human spermatozoa. Biol Reprod. 1998;59(5):1037-46.

28. Tremellen K. Oxidative stress and male infertility-a clinical perspective. Hum Reprod Update. 2008;14(3):24358. doi: 10.1093/humupd/dmn004.

29. Axelsson J, Bonde JP, Giwercman YL, Rylander L, Giwercman A. Gene-environment interaction and male reproductive function. Asian J Androl. 2010;12(3):298-307. doi: 10.1038/aja.2010.16.

30. Rubes J, Selevan SG, Sram RJ, Evenson DP, Perreault SD. GSTM1 genotype influences the susceptibility of men to sperm DNA damage associated with exposure to air pollution. Mutat Res. 2007;625(1-2):20-8. 